\title{
Failure Strength of Thin-walled Cylindrical GFRP Composite Shell against Static Internal and External Pressure for various Volumetric Fiber Fraction
}

\author{
S. Gohari, A. Golshan, M. Mostakhdemin, F. Mozafari, and A. Momenzadeh
}

\begin{abstract}
A study on a Circular cylindrical thin-walled shell failure made of GRP composite subjected to static internal and external pressure was carried out. The results were acquired using analytical and FEM simulation approaches for various volumetric fiber fractions. Fiber breakage, matrix breakage, interlaminate shear deformation, delamination shear deformation and micro buckling failure were investigated employing maximum failure criteria against internal and external pressure. One-ply cylindrical shell with fiber angle orientation of 0 degree was modeled in ABAQUS finite element simulation and the result was varied using analytical approaches. Moreover, the pressure fluctuations for various volumetric fiber fraction were quadratic according to plotted graphs. Meanwhile, MATLAB software was used for theoretical analysis. The comparison of two approaches was proved to be accurate. Subsequently, failure strength of various laminated GFRP cylindrical shell with different fiber angle orientations at each ply was studied for diverse volumetric fiber fraction factors. Stacking sequence, fiber angle orientations were mainly effective on failure strength.
\end{abstract}

Index Terms-Volumetric fiber fraction factor, internal and external pressure, GFRP composite cylindrical shell, failure strength, theoretical analysis, finite element simulation.

\section{INTRODUCTION}

The use of composite materials in pressure vessels and piping systems has been increasing recently [1-3]. The great portion of application has been related to the manufacturing and engineering designs, particularly, laminated composite pressure vessels with cylindrical geometry. Thus, the appropriate engineering designs concerning laminated composite structures require some crucial factors such as failure analysis which must be put into consideration.

Finite element method is a numerical method that can be used for solving engineering problems.

It is particularly useful for problems involving complex geometries, combined loading and material properties, in which the analytical solutions are not available. The failure factor can be obtained through numerical finite element (FEM) simulation and experimental approaches which can independently be used to validate the analytical solutions.

Manuscript received February 9, 2012; revised March 27, 2012.

S. Gohari and M. Mostakhdemin Faculty of Mechanical Engineering, Universiti Teknologi Malaysia, 81310, UTM Skudai, Malaysia (email: soheil.gohari7@gmail.com).

A. Golshan is with Faculty of Mechanical Engineering, University Putra Malaysia, UPM Selangor, Malaysia.

F. Mozafari is with Faculty of Mechanical Engineering, Universiti Teknologi Malaysia, 81310, UTM Skudai, Malaysia.

A. Momenzadeh is with Faculty of Civil Engineering, Universiti Teknologi Malaysia, 81310, UTM Skudai, Malaysia.
Classical plate theory can be used to obtain analytical solutions of laminated composite structures. Numerous researches have been carried out in composite pressure vessels design aspects and their manufacturing methods [49]. In this paper, Effect of Volumetric Fiber Fraction on Failure Strength of Thin-walled GFRP Composite Cylindrical Shell Externally Pressurized is investigated.

\section{THEORETICAL ANALYSIS OF COMPOSITE CYLINDRICAL SHELL}

In this study, the laminated cylindrical GFRP shell is modeled as a symmetrical laminated composite with no bending and twisting moments in each ply since the shell is considered thin. The fiber angle orientation (winding angle of fiber with respect to axial direction) is $\beta$, and the distance from mid-ply to the $K_{t h}$ ply is $h$. ply's thickness $\mathrm{t}$ is assumed to be constant. It can be obtained using Eq.1. Cylinder's mean radius $\mathrm{R}$ can also be obtained using Eq.2. The stress resultants in the geometric coordinate axes are stated in Eq.3.

$$
\begin{aligned}
& t=(H / k) \\
& R=r_{o}-(H / 2) \\
& {[N]=[A] \cdot[\varepsilon]}
\end{aligned}
$$

where, $\mathrm{k}$ is number of layers, $\mathrm{H}$ is total thickness, $r_{0}$ is cylinder's outer radius, $N$ is vector of stress resultants $[\mathrm{N} / \mathrm{m}]$, A stands for extensional stiffness matrix and $\mathcal{E}$ is strains vector. The relationship between stress and strains for the Kth orthotropic layer is represented in Eq.4.

$$
\sigma^{(K)}=\bar{Q}^{(K)} \cdot \varepsilon
$$

where $\sigma^{(K)}$ stands for vector of stresses for the Kth ply, $\bar{Q}$ is known as transformed material stiffness content (Refer to Appendix A). Local stress resultants can be obtained using Eq.5.

$$
[\sigma]_{K}^{\text {Local }}=[T] \cdot[\sigma]_{K}^{\text {Global }}
$$

where, $\mathrm{T}$ is transformation matrix (Refer to Appendix A) which varies as fiber angle orientation changes. Global load 
resultants, $N_{X}$ and $N_{\theta}$, applied per unit length $[\mathrm{N} / \mathrm{m}]$ in the axial and radial directions in shell element pressurized can be obtained using Eq. 6 and Eq.7, respectively. The shear stress value shown in Eq. 8 is equal to zero due to symmetry of laminated cylindrical dome and symmetrically loading.

$$
\begin{gathered}
\left|N_{X}\right|=|\operatorname{Pr}| \frac{r_{1}}{2}\left(2-\frac{r_{1}}{r_{2}}\right) \\
\left|N_{\theta}\right|=|\operatorname{Pr}| \frac{r_{1}}{2} \\
N_{\varphi \theta}=0
\end{gathered}
$$

where, $r_{2}$ is meridian radius which is infinite for cylindrical shell and $r_{1}$, in contrast, is radial radius of cylinder which is constant. Values of $r_{1}$ and $r_{2}$ in a shell are shown in Eq.9 and 10 , respectively.

$$
\begin{aligned}
& r_{1}=a \\
& r_{2}=\infty
\end{aligned}
$$

The material properties of Graphite reinforced Polymer are presented in Table.1. Reduced stiffness matrix and transformation matrixes both are dependent on the material properties of composite materials (Refer to appendix A). The compliance matrixes A, B and D of composite shell externally pressurized can be shown in Eq.11, Eq.12, Eq.13 and Eq.14, respectively. By substituting the Eq.9 and Eq.10 into the Eq. 6 and Eq.7, Values of global load resultants in circular cylindrical shell subjected to pressure can be obtained resulting in Eq.15 and Eq.16, respectively. Fig.1 shows the stacking sequences in a lamination.

$$
\begin{gathered}
{\left[\begin{array}{c}
N_{\varphi} \\
N_{\theta} \\
0 \\
0 \\
0 \\
0
\end{array}\right]=\left[\begin{array}{llllll}
A_{11} & A_{12} & A_{16} & B_{11} & B_{12} & B_{16} \\
A_{12} & A_{22} & A_{26} & B_{12} & B_{22} & B_{26} \\
A_{16} & A_{26} & A_{66} & B_{16} & B_{26} & B_{66} \\
B_{11} & B_{12} & B_{16} & D_{11} & D_{12} & D_{16} \\
B_{12} & B_{22} & B_{26} & D_{12} & D_{22} & D_{26} \\
B_{16} & B_{26} & B_{66} & D_{16} & D_{26} & D_{66}
\end{array}\right] \times\left[\begin{array}{c}
\varepsilon_{\varphi} \\
\varepsilon_{\theta} \\
\varepsilon_{\varphi \theta} \\
\mathrm{K}_{\varphi} \\
\mathrm{K}_{\theta} \\
\mathrm{K}_{\varphi \theta}
\end{array}\right]} \\
A_{i j}=\sum_{K=1}^{n}\left[\bar{Q}_{i j}\right]_{K}\left(h_{K}-h_{k-1}\right), i=1,2,6 ; j=1,2,6 \\
B_{i j}=\frac{1}{2} \sum_{K=1}^{n}\left[\bar{Q}_{i j}\right]_{K}\left(h_{K}^{2}-h_{K-1}^{2}\right), i=1,2,6 ; j=1,2,6 \\
D_{i j}=\frac{1}{3} \sum_{K=1}^{n}\left[\bar{Q}_{i j}\right]_{K} \\
N_{X}=\frac{|\operatorname{Pr}| \times R}{2}
\end{gathered}
$$

$$
N_{\theta}=\mid \operatorname{Pr} \times R
$$

Fig. 2 and Fig. 3 illustrate the effect of $V_{f}$ within interval of $V_{f}=[0.25,0.75]$ for various thin-walled GFRP cylindrical shells with different total thicknesses with $r_{0}=40 \quad[\mathrm{~mm}]$ and length $\mathrm{L}=230 \quad[\mathrm{~mm}]$ subjected to internal and external pressure, respectively. The cylindrical shells are assumed to be one layer with $\beta=0$. According to Fig.2 and Fig.3, it can be noticed that by increase in $V_{f}$, the absolute value of $P_{C r}$ rises quadratically for various total thicknesses for both internal and external pressure cases. However, by comparison of Fig. 2 and Fig. 3 , it can be noticed that the shell is more resistible against external pressure than internal pressure.

TABLE I: MATERIAL PROPERTIES

\begin{tabular}{ccc}
\hline Engineering Constant & Graphite Fiber & IMHS Epoxy [10] \\
\hline$E_{1}[G P a]$ & 220.0 & 3.447 \\
$E_{2}[G P a]$ & 13.70 & 3.447 \\
$G_{12}[G P a]$ & 8.960 & 1.276 \\
$v_{12}$ & 0.25 & 0.35 \\
$S_{u t}[M P a]$ & 2415.0 & 103.0 \\
$S_{u c}[M P a]$ & -2070.0 & -241.0 \\
$S_{u s}[M P a]$ & - & 89.60 \\
$\rho\left[k g / m^{3}\right]$ & 1772 & 1210 \\
\hline
\end{tabular}

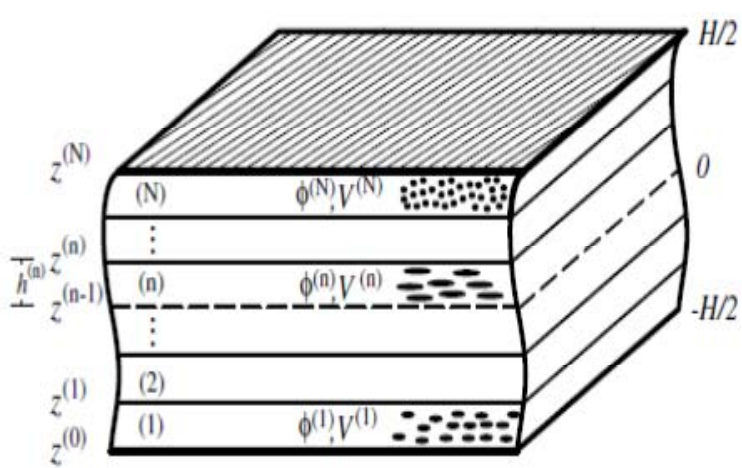

Fig. 1. Schematic of Lamination Geometry.

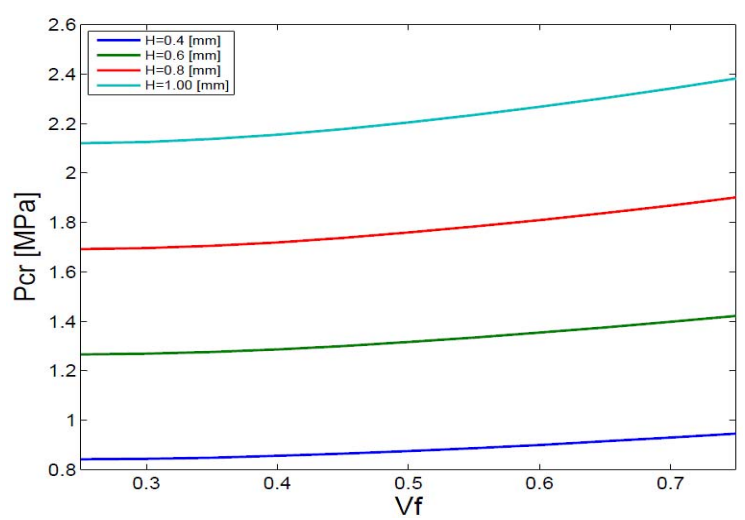

Fig. 2. Effect of $V_{f}$ on internal $P_{C r}$ in one-ply GFRP cylindrical shell and $\beta=0$. 


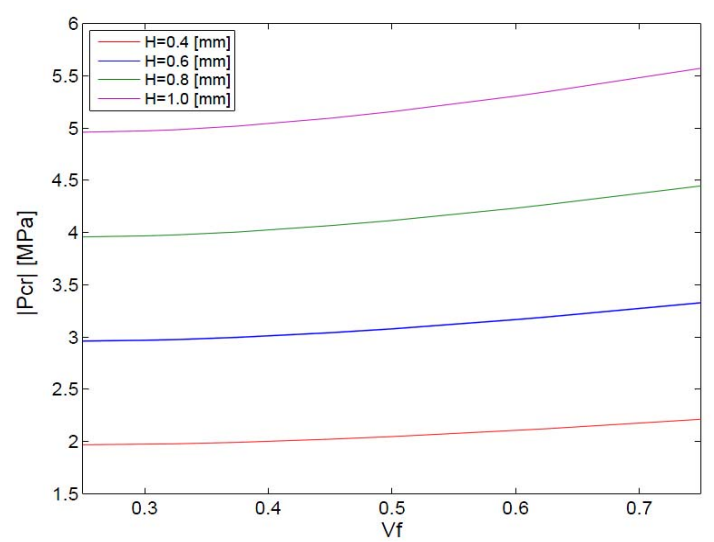

Fig. 3. Effect of $V_{f}$ on external $P_{C r}$ in one-ply GFRP cylindrical shell and $\beta=0$

\section{FEM SimULATION APPROACH}

In this step, one-ply circular cylindrical shell is simulated via ABAQUS FEM analysis. The aim is to find out the critical internal and external pressure $\left(P_{C r}\right)$ applied resulting in first-ply failure for various volumetric fiber fraction factors. Material properties are assigned to shell section, local material orientations are determined, the pressure and boundary conditions are applied, and the model is meshed using quadratic shell element with 8 degree of freedom and finally is analyzed in job step. The results are checked with analytical data acquired by MATLAB programming codes.

The comparisons of analytical solutions and FEM simulations for a one-layer GFRP cylindrical shell subjected to static internal and external pressure with total thickness of $0.4[\mathrm{~mm}]$ and fiber angle orientation of 0 degree are shown in Fig. 5 and Fig. 5, respectively. According to Fig 3 and Fig. 4, the critical internal and external pressure fluctuations VS $V_{f}$ are plotted for both analytical and FEM simulation. The error is proved to be insignificant. The schematic of one-ply GFRP cylindrical shell contour plot presenting critical transverse stresses $S_{22}$ to avoid matrix breakage is modeled in ABAQUS complete environment visualization for input data $\mathrm{H}=0.4[\mathrm{~mm}], \beta=0$ and $V_{f}=$ 0.25 for both internal and external pressure cases (Refer to Fig. 6 and Fig. 7).

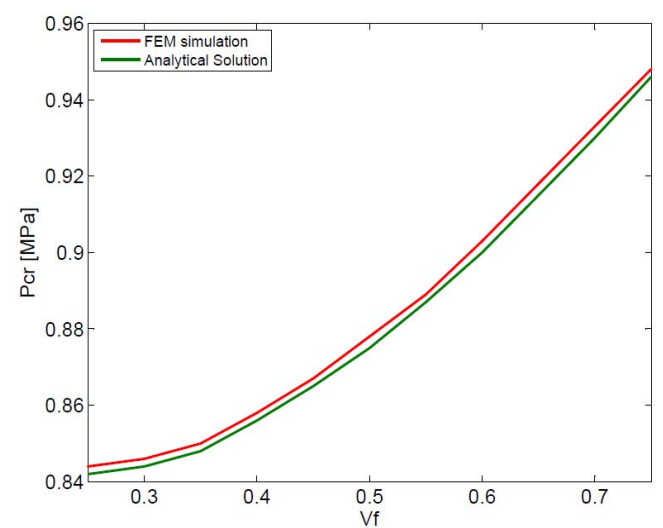

Fig. 4. Comparison of EFM and analytical approaches for GFRP cylindrical shell, $\beta=0, H=0.4[\mathrm{~mm}], V_{f}=0.25$.

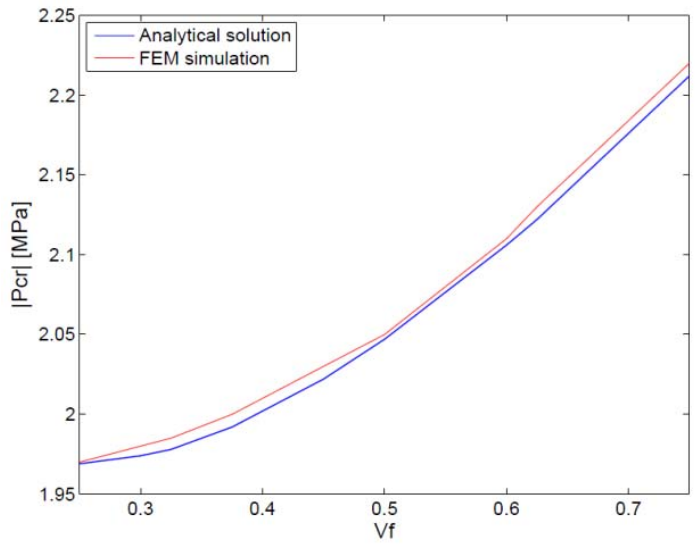

Fig. 5. Comparison of EFM and analytical approaches for GFRP cylindrical shell, $\beta=0, H=0.4[\mathrm{~mm}], V_{f}=0.25$.

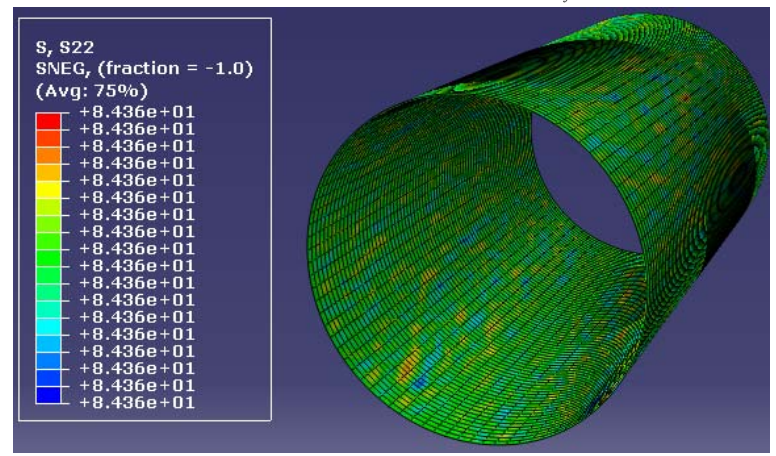

Fig. 6. Schematic of one-ply GFRP cylindrical shell color contour subjected to internal pressure, $\beta=0, H=0.4[\mathrm{~mm}], V_{f}=0.25$, Failure due to tensile matrix breakage (S22).

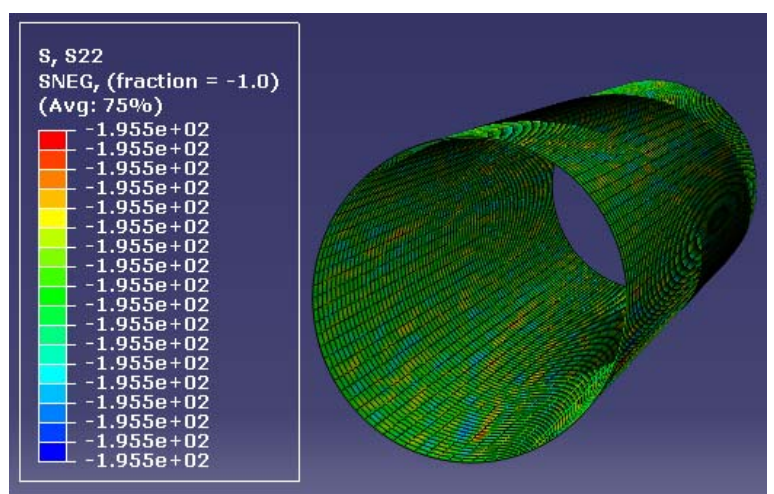

Fig. 7. schematic of one-ply GFRP cylindrical shell contour plot subjected to external pressure, $\beta=0, H=0.4[\mathrm{~mm}], V_{f}=0.25$, Failure due to compression matrix breakage (S22).

\section{AnAlytical Results For Multi-LAyERED GFRP CYLINDRICAL SHELL}

In this step, the analytical approach is used in order to find critical internal and external pressure applied on multilayer cylindrical GFRP shell with different stacking sequence based on various $V_{f}$ (Refer to Table.2). Language of technical computing MATLAB is used during analysis. The Critical internal and external pressure acquired analytically and their mode of failure to avoid first-ply failure considering each lamination is represented in TABLE III, TABLE IV, TABLE $\mathrm{V}$ and TABLE VI respectively.

TABLE II: PROPERTIES OF PRESSURE VESSELS 


\begin{tabular}{cc}
\hline Lamination Arrangement & Dimensions \\
\hline$\left[54^{\circ} /-54^{\circ}\right]_{s}$ & Outer radius $r_{0}=4[\mathrm{~cm}]$ \\
{$\left[45^{\circ} /-45^{\circ}\right]_{s}$} & Length $\mathrm{L}=23[\mathrm{~cm}]$ \\
{$\left[54^{\circ} /-54^{\circ} / 54^{\circ}\right]_{s}$} & Lamina Thickness $\mathrm{t}=0.1[\mathrm{~mm}]$ \\
{$\left[90^{\circ} / 0^{\circ} / 90^{\circ}\right]_{s}$} & $V_{f}=\{0.25,0.5,0.75\}$ \\
\hline
\end{tabular}

TABLE III: EFFCt OF STACKING SEQUENCE AND $V_{f}$ FACTORS ON FAILURE STRENGTH In LAMINATED GFRP CyLINDRICAL SHELLS SuBJeCted TO STATIC INTERNAL PRESSURE

\begin{tabular}{c|ccc}
\hline \multirow{2}{*}{ Lamination Arrangement } & \multicolumn{3}{|c}{ Critical Internal Pressure $\left(P_{C r}\right)$ [MPA] } \\
\cline { 2 - 4 } & $V_{f}=0.25$ & $V_{f}=0.5$ & $V_{f}=0.75$ \\
\hline$\left[54^{\circ} /-54^{\circ}\right]_{s}$ & 4.313 & 8.429 & 12.631 \\
{$\left[45^{\circ} /-45^{\circ}\right]_{s}$} & 2.834 & 2.966 & 3.246 \\
{$\left[54^{\circ} /-54^{\circ} / 54^{\circ}\right]_{s}$} & 4.622 & 8.852 & 13.256 \\
{$\left[90^{\circ} / 0^{\circ} / 90^{\circ}\right]_{s}$} & 6.365 & 12.544 & 16.645 \\
\hline
\end{tabular}

TABLE IV: EFFCT OF STACKING SEQUENCE AND $V_{f}$ FACTORS ON FAILURE STRENGTH IN LAMINATED GFRP CYLINDRICAL SHELLS SUBJECTED TO STATIC EXTERNAL PRESSURE

\begin{tabular}{c|ccc}
\hline \multirow{4}{*}{ Lamination Arrangement } & \multicolumn{4}{|c}{ Critical External Pressure $\left(P_{C r}\right)$ [MPA] } \\
\cline { 2 - 4 } & $V_{f}=0.25$ & $V_{f}=0.5$ & $V_{f}=0.75$ \\
\hline$\left[54^{\circ} /-54^{\circ}\right]_{s}$ & -3.697 & -6.947 & -7.426 \\
{$\left[45^{\circ} /-45^{\circ}\right]_{s}$} & -2.834 & -2.966 & -3.246 \\
{$\left[54^{\circ} /-54^{\circ} / 54^{\circ}\right]_{s}$} & -3.962 & -7.295 & -7.793 \\
{$\left[90^{\circ} / 0^{\circ} / 90^{\circ}\right]_{s}$} & -5.456 & -10.338 & -11.043 \\
\hline
\end{tabular}

TABLE V: FAILURE TYPES INVESTIGATION IN LAMINATED GFRP CYlindRICAL SHELls SubJeCted to STATIC InTERNAL PRESSURE With

\begin{tabular}{|c|c|c|c|}
\hline \multicolumn{4}{|c|}{ VARIOUS $V_{f}$ AND STACHING SEQUENCES } \\
\hline $\begin{array}{l}\text { Lamination } \\
\text { Arrangement }\end{array}$ & $V_{f}=0.25$ & $V_{f}=0.5$ & $\begin{array}{c}V_{f}= \\
0.75\end{array}$ \\
\hline$\left[54^{\circ} /-54^{\circ}\right]_{s}$ & Fiber Breakage & $\begin{array}{c}\text { fiber } \\
\text { Breakage }\end{array}$ & $\begin{array}{c}\text { Fiber } \\
\text { Breakage }\end{array}$ \\
\hline$\left[45^{\circ} /-45^{\circ}\right]_{s}$ & $\begin{array}{l}\text { Interlaminate } \\
\text { Shear } \\
\text { Deformation }\end{array}$ & $\begin{array}{c}\text { Interlaminate } \\
\text { Shear } \\
\text { Deformation }\end{array}$ & $\begin{array}{c}\text { Interlamin } \\
\text { ate Shear } \\
\text { Deformati } \\
\text { on }\end{array}$ \\
\hline$\left[54^{\circ} /-54^{\circ} / 54^{\circ}\right]$ & Fiber Breakage & $\begin{array}{c}\text { Fiber } \\
\text { Breakage }\end{array}$ & $\begin{array}{c}\text { Fiber } \\
\text { Breakage }\end{array}$ \\
\hline$\left[90^{\circ} / 0^{\circ} / 90^{\circ}\right]_{s}$ & Fiber Breakage & $\begin{array}{c}\text { Fiber } \\
\text { Breakage }\end{array}$ & $\begin{array}{c}\text { Matrix } \\
\text { Breakage }\end{array}$ \\
\hline
\end{tabular}

TABLE VI: FAILURE TYPES INVESTIGATION IN LAMINATED GFRP Cylindrical Shells Subjected to Static External Pressure With

\begin{tabular}{c|ccc}
\multicolumn{4}{c}{ VARIOUS ${ }^{V_{f}}$ AND STACHING SEQUENCES } \\
\hline \multirow{2}{*}{$\begin{array}{c}\text { Lamination } \\
\text { Arrangement }\end{array}$} & \multicolumn{2}{c}{ Type of Failure (Refer to Appendix. B) } \\
\cline { 2 - 4 } & $V_{f}=0.25$ & $V_{f}=0.5$ & $V_{f}=0.75$ \\
\hline $\left.54^{\circ} /-54^{\circ}\right]_{s}$ & Fiber Breakage & $\begin{array}{c}\text { Delamination } \\
\text { Shear } \\
\text { Interlaminate }\end{array}$ & $\begin{array}{c}\text { Delaminati } \\
\text { on Shear } \\
\text { Interlaminat } \\
\text { e Shear }\end{array}$ \\
{$\left[55^{\circ} /-45^{\circ}\right]_{s}$} & $\begin{array}{c}\text { Shear } \\
\text { Deformation }\end{array}$ & $\begin{array}{c}\text { Shear } \\
\text { Deformation }\end{array}$ & $\begin{array}{c}\text { Deformatio } \\
\text { n }\end{array}$ \\
{$\left[90^{\circ} / 0^{\circ} / 90^{\circ}\right]_{s}$} & Fiber Breakage & $\begin{array}{c}\text { Delamination } \\
\text { Shear }\end{array}$ & $\begin{array}{c}\text { Delaminati } \\
\text { on Shear }\end{array}$ \\
\hline
\end{tabular}

According to Table. 3 and Table.4, it is noticeable that the high strength against failure can be detected in the lamination $\left[90^{\circ} / 0^{\circ} / 90^{\circ}\right]_{s}$ for both internal and external pressure cases for all volumetric fiber fraction factors. In other hand, the low resistance can be inspected in the lamination $\left[45^{\circ} /-45^{\circ}\right]_{s}$ for both internal and external pressure cases. However, laminations $\left[54^{\circ} /-54^{\circ}\right]_{s}$ and $\left[54^{\circ} /-54^{\circ} / 54^{\circ}\right]_{s}$ have somehow same behavior concerning failure strength for one specific fiber fraction factor. Considering the effect of fiber fraction factor for one lamination, it is obvious that any increase in this factor leads in rise in failure strength.

The comparison between the results acquired based on the Table. 3 and Table. 4 proves the higher strength of the corresponding laminated cylindrical shells subjected to internal pressure than external pressure for all laminations.

TABLEB V and TABLE VI represent the type of failure occurring in corresponding cylindrical shells which are acquired employing maximum stress criteria mode. Each lamination has quite different failure mode. For instance, the lamination $\left[45^{\circ} /-45^{\circ}\right]_{s}$ is vulnerable to interlaminate shear deformation for all $V_{f}$ for both internal and external pressure cases.

Considering internal pressure cases and regardless of lamination $\left[45^{\circ} /-45^{\circ}\right]_{s}$, the fiber breakage failure can be detected for laminations $\left[54^{\circ} /-54^{\circ}\right]_{s}$ and $\left[54^{\circ} /-54^{\circ} / 54^{\circ}\right]_{s}$ for all corresponding volumetric fiber fractions. Lamination $\left[90^{\circ} / 0^{\circ} / 90^{\circ}\right]_{S}$ has fiber breakage failure for volumetric fiber fraction of $V_{f}=\{0.25,0.5\}$ and matrix breakage failure for volumetric fiber fraction of $V_{f}=\{0.75\}$.

Based on the data obtained for external pressure case and regardless of lamination $\left[45^{\circ} /-45^{\circ}\right]_{s}$, fiber breakage failure occurs for $V_{f}=\{0.25\}$ in whole laminations; however, delamination shear is detected for $V_{f}=\{0.5,0.75\}$.

\section{CONCLUSION}

As follows from foregoing analysis, the effect of volumetric fiber fraction factor $\left(V_{f}\right)$ on failure pressure was investigated for GFRP cylindrical shells subjected to internal and external pressure with various total thicknesses. It was noticeable that effect of $V_{f}$ is straight in failure strength of GFRP cylindrical shells. The behavior of internal and external $P_{C r}$ fluctuations was quadratic as $V_{f}$ varied. Subsequently, the theoretical results were validated by FEM simulation. In addition, the effect of stacking sequence for various laminations was put into consideration including type of failure and failure strength employing maximum stress criteria mode. Lamination $\left[90^{\circ} / 0^{\circ} / 90^{\circ}\right]_{s}$ was proved to be more resistance against failure pressure for different $V_{f}$ factors for both internal and external pressure cases; however, lamination $\left[45^{\circ} /-45^{\circ}\right]_{s}$, in contrast, showed 
weaknesses against failure pressure for all $V_{f}$ factors. Lamination $\left[45^{\circ} /-45^{\circ}\right]_{s}$ is totally vulnerable to interlaminate shear deformation for all $V_{f}$ factors for both internal and external pressure cases. In addition, by selecting appropriate arrangement of ply's winding angles, the best and optimal layups, which basically means high critical external pressure values at each ply, can be achieved.

\section{APPENDIX A}

The elements of the reduced stiffness matrix $[\bar{Q}]$ of a laminate shown in Eq.8, Eq9 and Eq.10 are described as

$$
\begin{aligned}
& \bar{Q}_{11}=Q_{11} c^{4}+2\left(Q_{12}+2 Q_{66}\right) c^{2} s^{2}+Q_{22} s^{4} \\
& \bar{Q}_{12}=\left(Q_{11}+Q_{22}-4 Q_{66}\right) c^{2} s^{2}+Q_{12}\left(c^{4}+s^{4}\right) \\
& \bar{Q}_{22}=Q_{11} s^{4}+2\left(Q_{12}+2 Q_{66}\right) c^{2} s^{2}+Q_{22} c^{4} \\
& \bar{Q}_{66}=\left(Q_{11}+Q_{22}-2 Q_{12}\right) c^{2} s^{2}+Q_{66}\left(c^{2}-s^{2}\right)^{2} \\
& \bar{Q}_{16}=-Q_{22} c s^{3}+Q_{11} c^{3} s-\left(Q_{12}+2 Q_{66}\right)\left(c^{2}-s^{2}\right) c s \\
& \bar{Q}_{26}=-Q_{22} c^{3} s+Q_{11} c s^{3}-\left(Q_{12}+2 Q_{66}\right)\left(c^{2}-s^{2}\right) c s
\end{aligned}
$$

The standard transformation matrix is

$$
[T]=\left[\begin{array}{ccc}
c^{2} & s^{2} & 2 c s \\
s^{2} & c^{2} & -2 c s \\
-2 c s & c s & \left(c^{2}-s^{2}\right)
\end{array}\right]
$$

where $\mathrm{c}$ is $\operatorname{Cos}(\beta)$ and $\mathrm{s}$ is $\operatorname{Sin}(\beta)$

The lamina stiffness matrix $[Q]$ elements can be represented as below

$$
\begin{gathered}
Q_{11}=\frac{E_{1}}{1-v_{12} \times v_{21}} \\
Q_{22}=\frac{E_{2}}{1-v_{12} \times v_{21}} \\
Q_{12}=\frac{v_{12} \times E_{2}}{1-v_{12} \times v_{21}} \\
Q_{16}=Q_{26}=0 \\
Q_{66}=G_{12}
\end{gathered}
$$

\section{APPENDIX B}

Simplified composite micromechanics equations for compressive strength are classified as below:

\section{A. For Longitudinal Compression}

Fiber Compression:

$$
S_{L 11 C} \approx V_{f} \times S_{f C}
$$

Delamination Shear:

$$
S_{L 11 C} \approx 10 S_{L 12 S}+2.5 S_{m T}
$$

Micro buckling:

$$
S_{L 11 C} \approx G_{m} \times\left[1-V_{f}\left(1-\frac{G_{m}}{G_{f 12}}\right)\right]^{-1}
$$

\section{B. Transverse Compression}

$$
S_{L 22 C} \approx\left[1-\left(\sqrt{V_{f}}-V_{f}\right) \times\left(1-\frac{E_{m}}{E_{f 22}}\right)\right] \times S_{m C}
$$

\section{Interlaminate Shear}

$$
S_{L 12 S} \approx\left[1-\left(\sqrt{V_{f}}-V_{f}\right) \times\left(1-\frac{G_{m}}{G_{f 12}}\right)\right] \times S_{m S}
$$

where, $S_{f C}, S_{m T}, G_{m}, G_{f 12}, E_{m}, E_{f 22}$ are fiber compressive strength, matrix transverse compressive strength, matrix shear module, fiber shear module, matrix elasticity module and fiber elasticity module, respectively.

\section{REFERENCES}

[1] S. V. Kulkarmi and C. H. Zweben, composites in pressure vessels and piping. PVP-PB-021, ASME, 1997.

[2] T. R. Tauchert, "Optimum design of a reinforced cylindrical Pressure Vessel," Journal of Composite. Mat., vol.15, pp. 390-402, 1981.

[3] H. Fukunaga and M. Uemura, "Optimum design of helically wound Composite pressure vessels," Journal of Composite Structure, vol. 1, pp. $31,49,1983$.

[4] H. Fukunaga and T. W. Chou, "Simplified design techniques for laminated cylindrical pressure vessels under stiffness and strength constrains," Journal of Composite, Mat., vol. 22, pp. 1157-1169, 1988.

[5] S. Adali, E. B. Sumers, and V. E. Verijenko, "Optimization of laminated cylindrical presser vessels under strength criterion," Journal of Composite Structure, vol. 25, pp. 305-312, 1993.

[6] T. Y. Kam, Y. W. Liu, and F.T. Lee, "First-ply failure strength of laminated composite pressure Vessels," Journal of Composite structure, vol. 38, no. 1-4, pp. 65-70, 1997.

[7] R. R. Chang, "Experimental and Theoretical Analysis of First-Ply Failure of Laminated Composite Pressure Vessel," Journal of Composite Structure, vol. 49, pp. 237-243, 2000.

[8] C. T. F. Roaa, "Bak Hock Huat, Tay Boon Chei, Chai Min Chong and M.D.A.Mackney, Buckling of GRP Hemi-Ellipsoidal Dome Shells under External Hydrostatic Pressure," Ocean Engineering, vol. 30, pp. 691-705, 2003.

[9] C.-C. Liang, H.-W. Chen, and C.-H. Wang, "Optimum Design of Dome Contour for Filament-Wound Composite Pressure Vessels Based on a Shape Factor," Journal of Composite Structures. Vol:58, pp.469-482, 2002.

[10] C. C. Chamis, "Simplified composite micromechanics equations for strength, fracture toughness, impact resistance and environmental effects," NASA Tech Memo 83696, Cleveland OH: Lewis Research Center, 1984. 


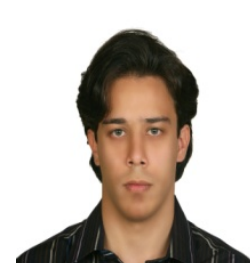

Soheil Gohari took an associate degree in mechanic-machineries from Iran. He furthered his higher education in bachelor program in the field of mechanical engineering (solid mechanic and design) from Azad University, Semnan branch, Iran. Subsequently, he graduated in master of engineering (Mechanical) from Universiti Teknologi

Malaysia (UTM). His is currently carrying out some researches at University Teknologi Malaysia in the field of mechanics (Behavior and Failure analysis of Hybrid Pressurized Components subjected to Pressure and Impact Loading). His research interests are single and multi-objective optimization problems, computational mechanics, finite element analysis and its application, advanced engineering materials such as composite and hybrid and their applications and pressure vessel designs.

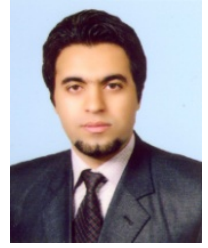

Abolfazl Golshan took a degree in advanced manufacturing technology from Isfahan University of Technology, Iran. His interests are modeling problems, single and multi-objective optimization of manufacturing processes, composite materials, computational mechanics, and finite element analysis. He is currently studying at University Putra Malaysia.

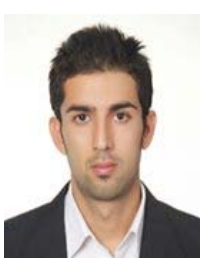

Mohammad Mostakhdemin graduated in bachelor program from Azad University, Semnan branch, Iran in the field of solid mechanic and design. He is currently taking a master program at Universiti Teknologi Malaysia (UTM) in field of master of engineering (Mechanical). His research interests are mechanic of advanced materials, fnite element analysis.

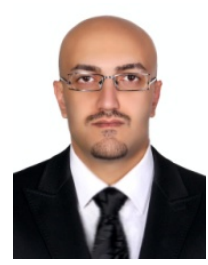

Farzin Mozafari graduated in bachelor program from Azad University, Central Tehran branch, Iran in the field of solid mechanic and design. He is currently taking a master program at Universiti Teknologi Malaysia (UTM) in field of master of engineering (Mechanical). His research interests are mechanic of advanced materials, finite element analysis, pressure vessel designs and computational fluid dynamic.

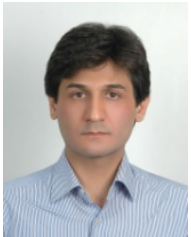

Alireza Momenzadeh took a degree in bachelor program with degree of specialization in civil engineering. He is currently studying at master of civil engineering (structure) at Universiti Teknologi Malaysia (UTM). His research interest is space structures. 